2021-11

How does a country's developmental status affect ambient air quality with respect to particulate matter?

Johnson, $\mathrm{R}$

http://hdl.handle.net/10026.1/18826

10.1007/s13762-020-03072-6

International Journal of Environmental Science and Technology

Springer Science and Business Media LLC

All content in PEARL is protected by copyright law. Author manuscripts are made available in accordance with publisher policies. Please cite only the published version using the details provided on the item record or document. In the absence of an open licence (e.g. Creative Commons), permissions for further reuse of content should be sought from the publisher or author. 
- Source: International Journal of Environmental Science \& Technology (IJEST) . Nov2021, Vol. 18 Issue 11, p3395-3406. 12p.

- Author(s): Johnson, R.; Rieuwerts, J.; Comber, S. D. W.

\author{
- Author(s): Johnson, R.iRieuwerts, Ji Comber, S. D. W.
}

\title{
How does a country's developmental status affect ambient air quality with respect to particulate matter?
}

Abstract

Ambient particulate matter pollution is a serious threat to public health, the global economy and the wider environment. Recent World Health Organisation figures show 92\% of the world lives in an area that exceeds the organization's air quality guideline. Between $87-90 \%$ of all deaths from air pollution occur in Low-Middle Income Countries (subcategorised as Least Developed Countries, Less Economically Developed Countries and Newly Industrialising Countries in this study), potentially showing a relationship between effects of air pollution and development. This research investigates how the developmental levels of a country can play a key role in determining its air pollution, with a focus on Particulate Matter $\left(\mathrm{PM}_{10}\right.$ and $\left.\mathrm{PM}_{2.5}\right)$ pollution. Results from primary and secondary literature collected between 2009-2017, show that $\mathrm{PM}_{10}$ and $\mathrm{PM}_{2.5}$ pollution concentrations were higher in countries with less development, with the highest levels found in Less Economically Developed Countries, and the least found in More Economically Developed Countries/High Income Countries. There is also exceedingly high levels reported in air from NICs and the Least Developed Country used in this study. In accordance with this finding, the highest observed $\mathrm{PM}_{10}$ level was $592 \mu \mathrm{g} / \mathrm{m}^{3}$ in Onitsha, Nigeria. The highest deaths per capita were found in a NIC, China. Other important factors in determining PM levels included geographical location and natural sources of PMs. PM pollution increases between countries with different developmental levels were noted to be correlated to a number of socioeconomic factors, as represented by the Human Development Index.

Key words: particulate matter; air quality; urban; health; economic development; developing world 


\section{Introduction}

With the advancement of technology and legislation in the UK (Department of Environment, 1995), Europe (EU, 2010, 2018) and worldwide (United Nations, 2019) there have been reductions in the release of certain harmful airborne pollutants in some countries. However, with a global population pursuing economic growth and rapid development, the environment and air quality is still a great cause for concern. Whilst levels of ambient air pollution (AAP) are reported to be reducing in more developed parts of the world, in countries with large scale manufacturing industries or less developed countries that see AAP as an acceptable consequence of growth, levels are surpassing dangerously toxic levels, leading to a global crisis (WHO, 2016; Fang et al., 2016).

To classify the development levels used in this research, literature produced by international bodies such as the United Nations (UN) 'classification of countries' report (2014), the World Bank and the International Monetary Fund (IMF) have been used. These classifications are determined by a number of economic and socioeconomic factors such as Gross National Income (GNI) and the Human Development Index (HDI). These classifications are split into the following categories; More Economically Developed Countries (MEDCs) or High-Income Countries (HICs), these include the UK and the USA, and Low to Middle Income Countries (LMICs). For the purpose of this research, the observed LMICs are further categorised as Newly Industrialising Countries (NICS) as defined by the IMF (India and China), Less Economically Developed Countries (LEDCS) (Nigeria and Pakistan), which are countries that fall into the 'developing' countries category under UN criterion, but fall outside the IMF's definition of an NIC or the UN definition of a least developed country (LDC), and finally the aforementioned LDCs, as defined by the UN (Uganda).

One well researched indicator of air quality is particulate matter (PM) which is defined according to its coarse particle size, with $\mathrm{PM}_{10}$ ( $\leq 10$ micrometers in size) and $\mathrm{PM}_{2.5}$ ( $\leq 2.5$ micrometers) being the most widely studied and observed (Bourdrel et al., 2017). PM can consist of a number of items; oxides, metal salts, organic materials, carbon and ammonium (nitrate and sulphate). The composition of PM can vary greatly based on where it is found, an example being in an urban environment where it may mainly consist of vehicular emissions (Royal College of Physicians, 2016). PM can exist in the atmosphere and airways from days to weeks and originate from both anthropogenic and natural sources (Barmpadimos et al., 2011). These sources include the combustion of fossil fuels (PM 2.5 ), nonexhaust vehicle emissions like tyre/brake particles, mining, construction and demolition $\left(\mathrm{PM}_{10}\right)$. Natural sources can include forest fires, volcanic activity and transformation of gaseous species (PM 2.5$)$ along with resuspension of soil dust $\left(\mathrm{PM}_{10}\right)$ (Barmpadimos et al., 2011). PM pollution has serious implications on human health, the global economy and the wider environment. A recent World Bank 
study (2016) found known economic losses linked to air pollution totalled more than $\$ 5$ trillion annually. The same study found that some LMICs, like Vietnam, see economic losses that equate to around $7.5 \%$ of their annual nominal GDP. Due to its substantial known implications, PM pollution should be considered of great importance in today's society. However, due to its size and lack of any odour, it is virtually invisible to the public eye and therefore can escape the public notice (Rieuwerts, 2016).

Besides PM, the other most common air pollutants include ozone, nitrogen oxides $\left(\mathrm{NO}_{2}\right.$ and $\left.\mathrm{N}_{2} \mathrm{O}\right)$, sulphur dioxide $\left(\mathrm{SO}_{2}\right)$ and carbon monoxide $(\mathrm{CO})$, all of which can have severe health effects. Worldwide around 7 million people die due to air pollution annually with 3 million dying from AAP (WHO, 2016). Importantly, the majority of these deaths come as a result of PM pollution, which has the most widespread health implications (WHO, 2016) and hence is the focus of this study, due to its potency and destructive potential. The primary diseases linked to air pollution are lung cancer, cardio vascular disease (CVD), chronic obstructive pulmonary disease (COPD) (which includes asthma and bronchitis) and stroke (Harrison, 2010, Rieuwerts, 2016 and WHO, 2016). The WHO (2016) consider stroke and ischemic heart disease (included in the CVD bracket) as the main causes of mortality from air pollution. In addition to this, more recent research has found links to increased rates of diabetes mellitus, increases in occurrences of neurological conditions like Alzheimers and even higher rates of pre-term birth (RCP, 2016; Roux et al., 2017).

PM is associated strongly with CVD (Yin et al., 2017), with much research conducted into this relationship. A 2015 and 2017 study found a $10 \mu \mathrm{g} / \mathrm{m}^{3}$ rise in long term exposure to $\mathrm{PM}_{2.5}$ is associated with a rise in CVD mortality of $6.2 \%$ and $11 \%$ respectively (Bourdrel et al., 2017). When considering areas with exceptionally high PM levels, such as Onitsha, Nigeria, which has a reported annual mean ambient $\mathrm{PM}_{10}$ value of $594 \mu \mathrm{g} / \mathrm{m}^{3}$, this can have serious consequences for CVD rates (Ngele and Onwu, 2015).

COPD and lung cancer can be caused due to the fact that $\mathrm{PM}_{10}$ and $\mathrm{PM}_{2.5}$ can travel deep into the bronchi of the lung, with the smaller $\mathrm{PM}_{2.5}$ penetrating deeper into the alveoli and adding harmful pollutants to the bloodstream like carcinogenic Polycyclic Aromatic Hydrocarbons (PAHs) (RCP, 2016). Another major health implication from PM pollution is the causation of strokes, the leading cause of death from PM pollution (WHO, 2016 and Yin et al., 2017). A study by Fang et al. (2016) postulated that $\mathrm{PM}_{2.5}$ can now be considered more hazardous as smoking and is responsible for more deaths in major cities in China. 
97 As around $92 \%$ of people live in areas that have AAP that exceeds the WHO Air Quality Guidelines

98 (AQG) (WHO, 2016) $)^{1}$, this is a serious public health issue. This is particularly true of cities based in LEDCs

99 and LDCs where $98 \%$ of cities with a population of $>100,000$ do not meet the WHO Air Quality

100 Guidelines (AQG) (WHO, 2016). This figure is in contrast to cities in MEDCs, where $56 \%$ of these cities

101 do not meet WHO AQG (WHO, 2016). Thus, there appears to be a clear divide between the air quality

102 in more developed countries versus those that are less developed (see Figure 1).

103

\footnotetext{
${ }^{1}$ The WHO AQG at the time of writing is $10 \mu \mathrm{g} / \mathrm{m}^{3}$ (annual mean) for $\mathrm{PM}_{2.5}$ and $20 \mu \mathrm{g} / \mathrm{m}^{3}$ (annual mean) for $\mathrm{PM}_{10}$. Available at: who.int/news-room/fact-sheets/detail/ambient-(outdoor)-air-quality-and-health $\left(28^{\text {th }}\right.$ January 2020).
} 


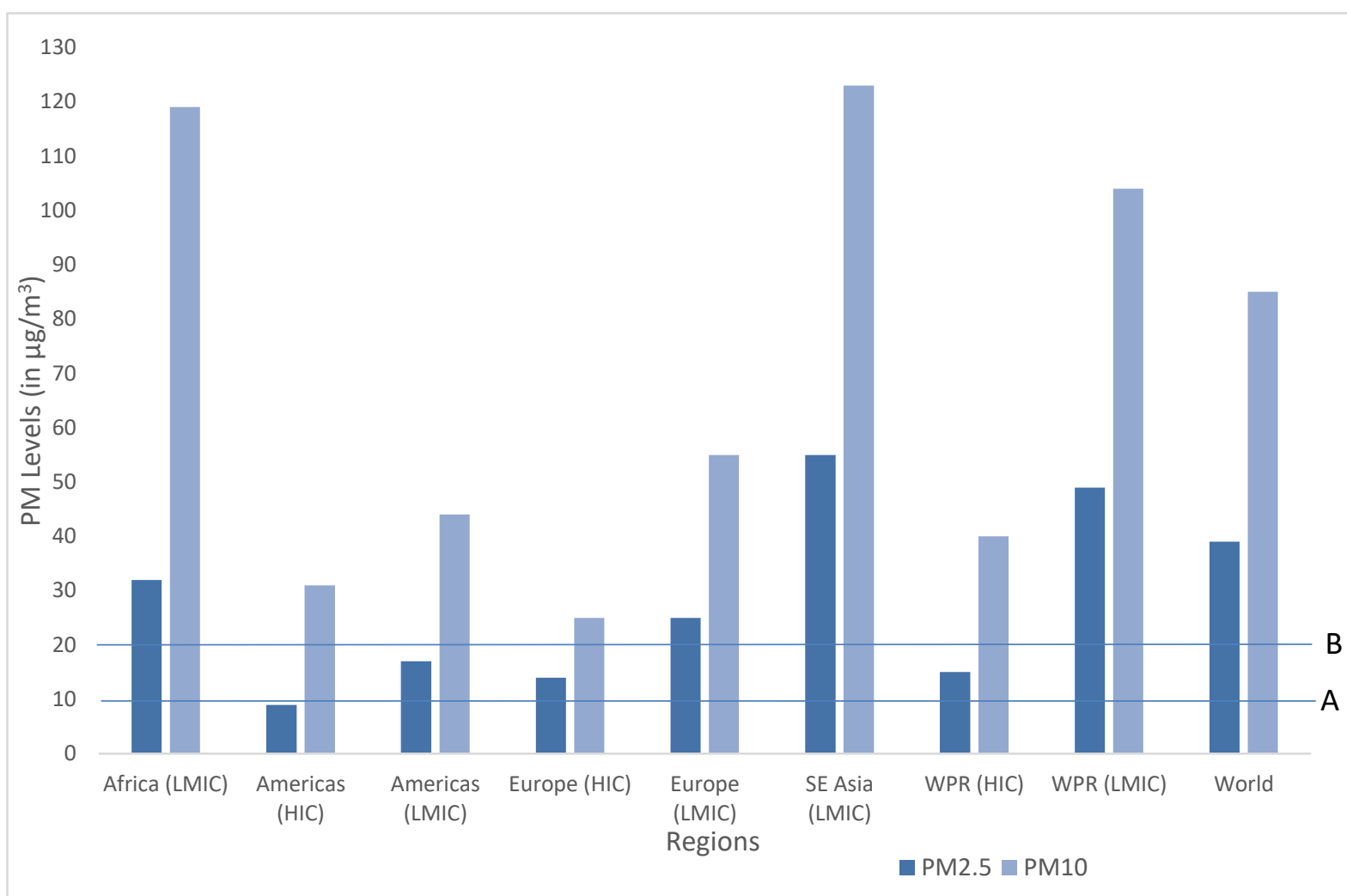

Figure $1 \mathrm{PM}_{2.5}$ and $\mathrm{PM}_{10}$ levels in different regions alongside their developmental status, graph constructed with data taken from the WHO database (2016). Data compiled between 2008-2015. The WHO annual AQG is represented by ' $A$ ' and ' $B$ ' for $P M_{2.5}$ and $P^{2} M_{10}$ respectively. 'WPR' refers to Western Pacific Region.

Consequently, the objectives of this research are to investigate the link between the developmental classification of a country and its ambient air pollution, with a focus on the two main forms of PM $\left(\mathrm{PM}_{10}\right.$ and $\left.\mathrm{PM}_{2.5}\right)$. The research will establish and examine the statistically significant relationship between these two variables, using national annual mean PM levels alongside annual mean levels in cities of comparable size in countries of differing developmental level.

\section{Methods}

This study examines the PM pollution of cities within countries of differing developmental levels, MEDCs/HICs and LMICs (which, for this study incorporates NICs, LEDCs and LDCs). The study includes:

- 5 LMICs; 2 NICs (India and China), 2 LEDCs (Nigeria and Pakistan) and 1 LDC (Uganda)

All of these countries are included in this research; however, the detailed discussion primarily places a focus on the UK, China and Nigeria. To determine the classification of a country's developmental level, predetermined classification levels identified by the UN, IMF and World Bank are used in this study, 
with substantial weight given to the United Nations 'Classifications of Countries Report' (2014). These bodies encompass metrics such as GNI, GDP and HDI as indicators of development.

125

126

127

128

129

130

131

132

133

134

135

136

137

138

139

140

141

142

143

144

145

146

147

148

149

150

151

152

153

\subsection{Air Quality Data}

The wealth of data made available by the WHO (2018) in the form of its World Air Pollution Database, forms the basis of this research, with secondary data from the selected countries for this research extracted from this database, analysed and subjected to rigorous statistical evaluation and scrutiny. This database compiles extensive datasets from both governmental run and funded air pollution monitoring stations, predominantly based in key cities, and third-party air pollution studies and reporting (where central government has no such monitoring facilities). For this study, data was extracted from all recorded urban locations present within the database for each selected country, with the sum-total averaged to represent the indicative PM levels. As some datasets from the WHO database are taken from independent reports, particularly in LMICs, it must be noted that data quality may not be as high as in developed countries where the availability and presence of centrally government funded 24 hour monitoring stations exists. Whilst this is not a perfect solution, currently there exists no better or alternative dataset, publicly available, in which to undertake a study such as this. Data used for this study ranged from 2009-2015, with the lion's share taken from 2013-14. During this period, it is considered that no significant events that may have had the ability to significantly alter the findings of this study occurred. Due to limitations within the datasets for certain selected countries, this varied time range was unavoidable, but is not considered to undermine the findings.

\subsection{Socio-economic data}

GNI and GDP data used in establishing development metrics come from the World Bank (2016b), whereas HDI data is compiled by the United Nations Human Development Programme (2016). Whilst it is accepted that these indicators are not faultless, they present the best opportunity to categorise and divide the countries in these studies into relevant groups.

\subsection{Statistical analysis methods used}

A suite of statistical tests was applied to the data to test the relationships proposed in this research. These included $\mathrm{P}$ tests, R-tests and Spearman rank tests, to establish correlations and statistically significant links between the variable used to measure development, in this research this was the HDI of a country, and the annual mean PM pollution levels of the selected countries.

\section{RESULTS and DISCUSSION}

\subsection{PM concentrations and economic development}


The highest annual mean $\mathrm{PM}_{10}$ levels (from years between 2009-2015) were observed in the LEDCs, followed by the LDC, Uganda. The NICs were lower and the MEDCs lower still. The highest individual recording for annual mean ambient $\mathrm{PM}_{2.5}$ and $\mathrm{PM}_{10}$ levels were found in selected areas of Nigeria, although Nigeria overall was lower than Pakistan. An example of this includes the city of Onitsha which had a $\mathrm{PM}_{10}$ value of $594 \mu \mathrm{g} / \mathrm{m}^{3}$ based on daytime monitoring but considered annually representative (WHO, 2016). Furthermore, this is not only the highest level observed in this study but also the highest recorded level of anywhere in the World based on information provided by the WHO database (Ngele and Onwu, 2015).

To analyse the statistical link between air quality and development level, HDI (UN 2016 figures) and GDP (World Bank 2016 figures) are tested against mean PM annual levels (WHO 2016 database and Kirenga et al., 2015 figures as shown in Table 2 and Figure 2). In addition to this, deaths from AAP are compared against these development factors as well.

The $\mathrm{HDI}$ and $\mathrm{PM}_{2.5}$ and $\mathrm{PM}_{10}$ values are found to be significantly correlated (Spearman's Rank Correlation Coefficient (SRCC) $-r=-0.75 p=0.05$ and $r=-0.82 p=0.02$ respectively). The same observation can be made for GDP and $\mathrm{PM}_{2.5}$ and $\mathrm{PM}_{10}(\mathrm{r}=-0.96 \mathrm{p}=0.0005$ and $\mathrm{r}=-0.82$ and $\mathrm{p}=0.02$ respectively). Thus, we can interpret that a reduction in GDP or HDI, is significantly correlated to PM levels of the selected countries in this study. Furthermore, whilst the total deaths and deaths per $100,000$ capita from AAP were found to be significantly correlated ( $r=0.89$ and $p=0.01)$, this is not the case when comparing these metrics with HDI. Correlation tests between total deaths from AAP and HDI ( $r=0.11$ and $p=0.82)$ and per 100,000 capita deaths from AAP and HDI ( $r=-0.14$ and $p=0.76)$ show weak insignificant correlations. Thus, as HDI decreases, attributable deaths from AAP does not necessarily appear to rise. However, this may be distorted by the increased sophistication of the reporting techniques used by more developed countries. In LMIC countries, due to limited to nonexistent funding for environmental monitoring, air quality data has to be obtained manually using portable photometric laser-based particle counter equipment (Ngele and Onwu, 2015). This is not the case in many HICs, including those incorporated in this study, where 24 hour monitoring stations have been established and are centrally funded (WHO, 2016). It is worth noting that correlation does not mean causation. However, in this case the two factors do appear to be linked. 
Table 2: Shows development indicators including GDP per capita and HDI (represented as a decimal out of 1.0 with 1 being the highest and 0 the lowest) PM levels and total and per 100,000 capita deaths from AAP

\begin{tabular}{|c|c|c|c|c|c|}
\hline Country & $\begin{array}{l}\text { GDP per Capita } \\
\text { (World Bank, 2016) }\end{array}$ & $\begin{array}{l}\text { HDI (UN, } \\
2016)\end{array}$ & $\begin{array}{l}\mathrm{PM}_{2.5} \text { and } \mathrm{PM}_{10} \\
\text { annual mean (WHO, } \\
2016)\end{array}$ & $\begin{array}{l}\text { Total } \\
\text { attributable } \\
\text { deaths to AAP } \\
\text { (WHO, 2016) }\end{array}$ & $\begin{array}{l}\text { Deaths per } \\
100,000 \\
\text { capita (WHO, } \\
2016 \text { ) }\end{array}$ \\
\hline USA & $\$ 57,466$ & 0.920 & 9 and $16 \mu \mathrm{g} / \mathrm{m}^{3}$ & 38,043 & 12 \\
\hline UK & $\$ 39,889$ & 0.909 & 12 and $18 \mu \mathrm{g} / \mathrm{m}^{3}$ & 16,355 & 26 \\
\hline China & $\$ 8,123$ & 0.624 & 52 and $84 \mu \mathrm{g} / \mathrm{m}^{3}$ & $1,032,833$ & 76 \\
\hline India & $\$ 1,709$ & 0.738 & 59 and $107 \mu \mathrm{g} / \mathrm{m}^{3}$ & 621,138 & 49 \\
\hline Nigeria & $\$ 2,177$ & 0.527 & 33 and $202 \mu \mathrm{g} / \mathrm{m}^{3}$ & 46,750 & 28 \\
\hline Pakistan & $\$ 1,468$ & 0.550 & 88 and $339 \mu \mathrm{g} / \mathrm{m}^{3}$ & 59,241 & 33 \\
\hline Uganda & $\$ 615$ & 0.493 & $\begin{array}{l}132^{*} \text { and } 170 \mu g / \mathrm{m}^{3} \\
\text { (Kirenga et al., 2015) }\end{array}$ & 7,989 & 23 \\
\hline
\end{tabular}

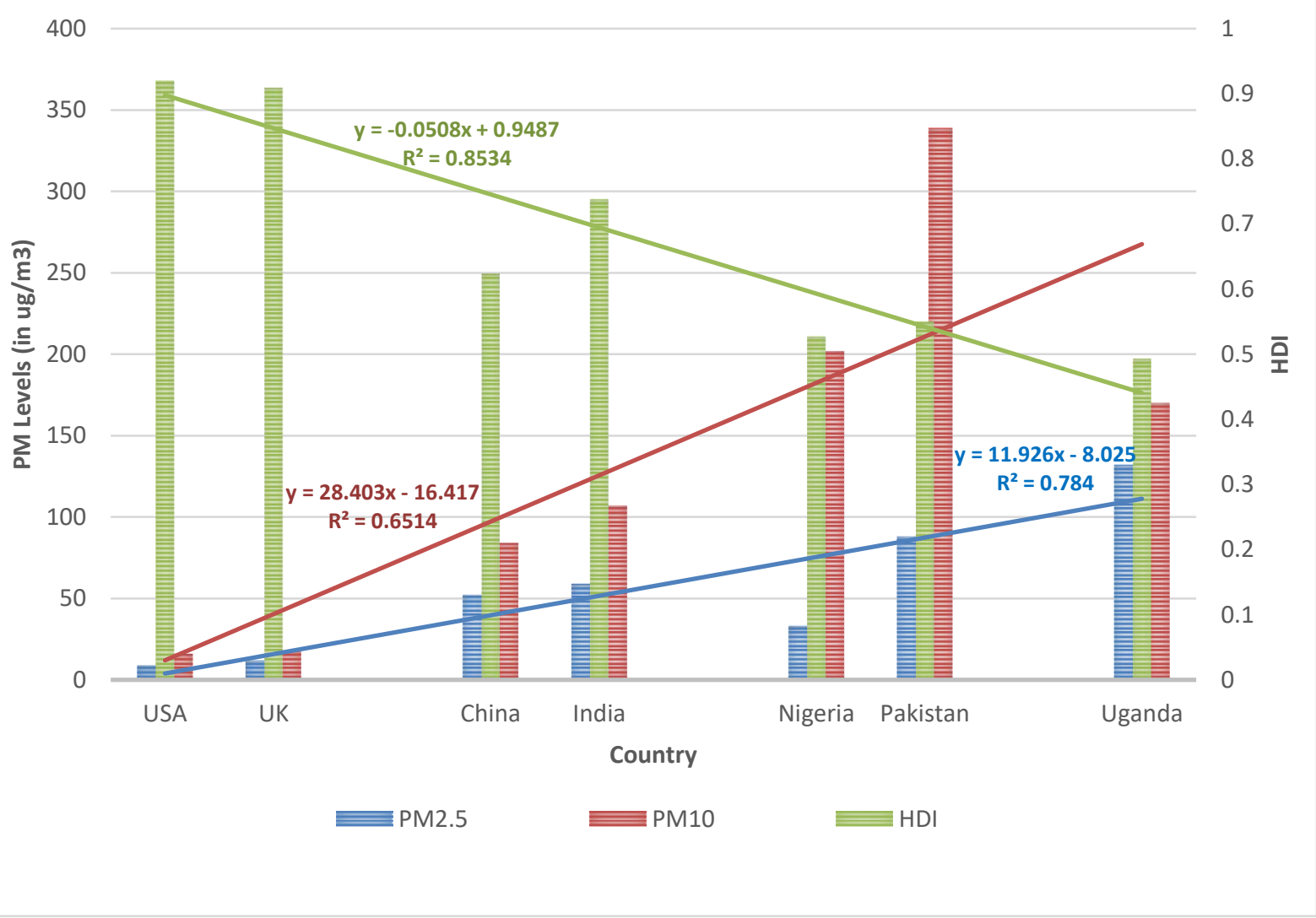

Figure 2 PM levels compared with HDI with associated linear trendlines. Countries are portrayed in descending development level; from left to right. 
The city of Haikou (pop. 2million) in China (an NIC) boasts the lowest $\mathrm{PM}_{2.5}$ values of any major city in China (with a population of $<1$ million), with annual mean $\mathrm{PM}_{2.5}$ levels of $22 \mu \mathrm{g} / \mathrm{m}^{3}$ (WHO, 2016). This is due to an action plan set out in 1995 to tackle environmental and social issues. This is a good example of a highly industrial city within an NIC that does not have extremely high PM levels.

Another example of this is Curitiba (pop. 1.75million) in Brazil where $\mathrm{PM}_{2.5}\left(11 \mu \mathrm{g} / \mathrm{m}^{3}\right)$ and $\mathrm{PM}_{10}$ $\left(24 \mu \mathrm{g} / \mathrm{m}^{3}\right)$ levels are comparable to those of cities in MEDCs. This was brought about by the 'Planeamiento Urbano' urban plan established in 1965 and is still ongoing. The plan put a focus on improving public transport, maintaining green spaces within the city and implementing efficient urban planning and design (Soltani and Sharifi; 2012; Macedo, 2013).

These examples demonstrate that not all major cities in NICs and LEDCs have higher levels of PM 2.5 and $\mathrm{PM}_{10}$ than their counterparts in MEDCs/HICs. However, overall the data clearly shows ambient PM levels are higher in countries with lower developmental level and that these examples are clearly anomalies within their regions.

Over the last century, the UK has transitioned from a highly industrial economy moved into the tertiary sector, leading to dramatic reductions in overall air pollution, especially from the industrial/manufacturing sectors. The heavy polluting burden associated with the manufacturing industry has shifted to less developed countries, often NICs like India and China (Rieuwerts, 2016), consequently, the UK has seen a substantial reduction in $\mathrm{PM}_{2.5}(42 \%)$ and $\mathrm{PM}_{10}(51 \%)$ emissions since 1990 's, because of this as well as increased legislation (DEFRA, 2017). However, with this shift into the tertiary sector came economic growth and an increase in vehicle ownership (United Kingdom Department for Transport, 2016). As a result, road transport is the $3^{\text {rd }}$ largest contributor to PM emissions in the UK after combustion in industry (manufacturing processes) and other production processes (including construction, mining and quarrying) (DEFRA, 2017). Electricity production is also a key source; the UK currently relies on the burning of fossil fuels for around $75 \%$ of the country's energy production (Rieuwerts, 2016).

The majority of PM pollution in China comes from manufacturing and energy production alongside vehicular emissions from road transport, all of which lead to a substantial number of deaths (Fang et al., 2016). Due to continual rapid expansion of industry and a rising number of cars, the national mean concentration of $\mathrm{PM}_{2.5}$ in China rose from $59 \mu \mathrm{g} / \mathrm{m}^{3}$ in 2010 to $77 \mu \mathrm{g} / \mathrm{m}^{3}$ in 2013 (Fang et al., 2016).

\subsection{Health impacts of PM}

The WHO (2016) estimates that around 16,355 deaths in the UK result from AAP annually. Whilst this may seem relatively low, it worth noting national studies (RCP, 2016) report a much higher figure of 
28,000 deaths annually. Furthermore, the basic reporting of rate of deaths per 100,000 capita, when looking at WHO (2016) figures, sits at 26, more than double that of the USA (12).

227 Overall, total deaths and deaths per 100,000 capita (Figure 3) were found to be highest in the NICs in 228 this study, followed by LEDCs and finally the MEDCs. WHO (2016) figures are used here as the organisation provides the most expansive free to access dataset currently available. As AAP figures are also taken from the WHO, using this dataset ensures consistency throughout this report.

Analysis of other studies found similar results. Looking at global rankings produced by Giannadaki et al. (2016), MEDCs have the lowest values of premature deaths per capita associated with $\mathrm{PM}_{2.5}$ and $\mathrm{PM}_{10}$ pollution, with NICs like China and India the highest rates followed closely by LEDCs with significant natural inputs, from desert dust or wildfires, such as Pakistan and Nigeria (Giannadaki et al., 2016). Health effects of PM pollution in China are considerable (Fang et al., 2016). Fang et al. (2016) reported that between 2004 and 2010, annual global premature deaths associated with $\mathrm{PM}_{2.5}$, rose from 800,000 to 3.2 million. From this figure, $72 \%$ of all deaths came from Asia (Apte et al., 2015) with the majority coming from China.

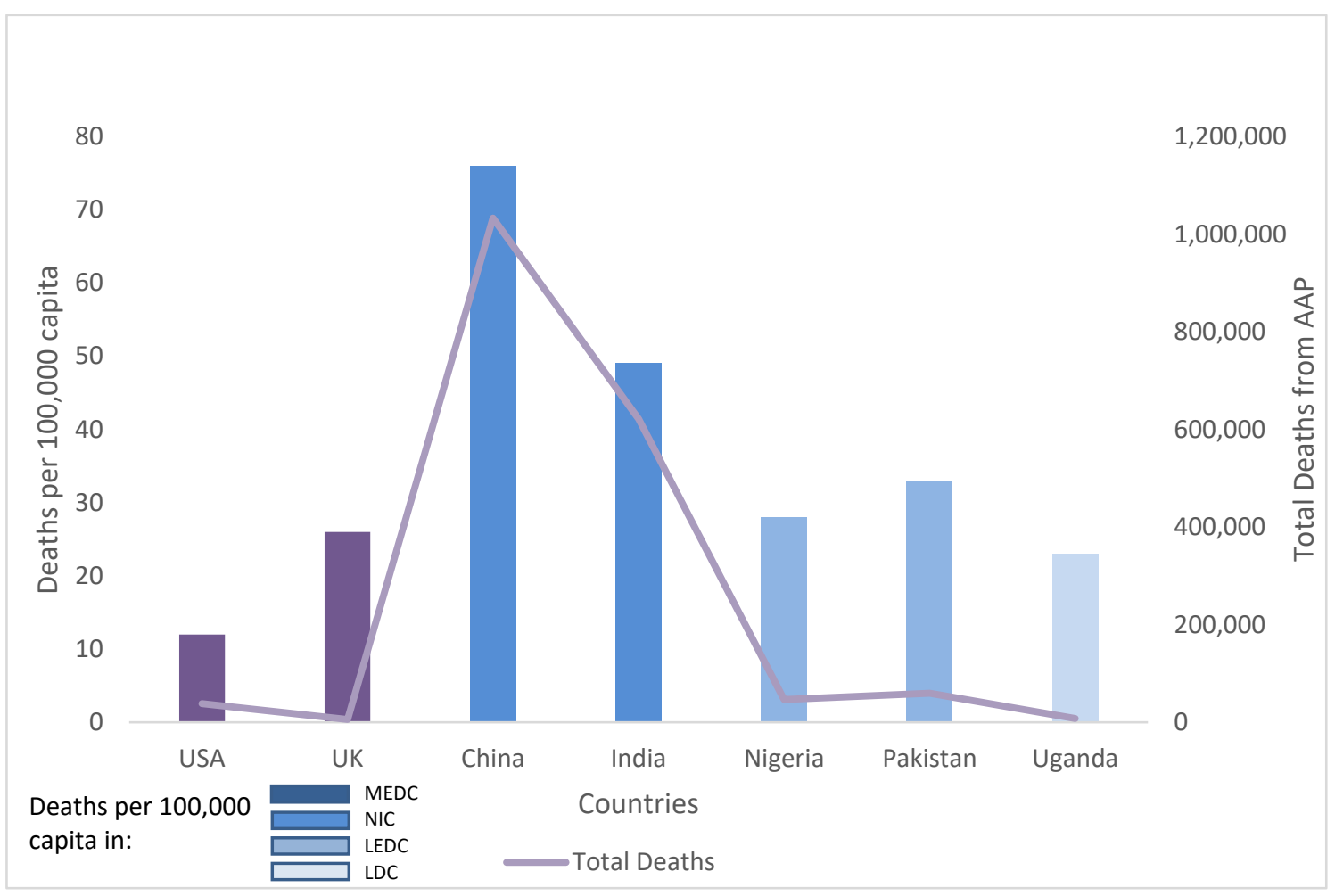
for this study. Graph constructed from data taken from the WHO (2016). 
LDCs including Sudan, a country not included in this study, feature lower down on the top 20 list for most $\mathrm{PM}_{2.5}$ deaths by country (Giannadaki et al., 2016), but Uganda, the LDC used for this study does not make it onto this list. This could possibly be due to its relatively small population or the inherent lack of data from the country (Kirenga et al., 2015). Giannadaki et al (2016) also reported that up to $68 \%$ and $26 \%$ of all $\mathrm{PM}_{2.5}$ related deaths, in Nigeria and Pakistan respectively, could be linked to natural sources such as desert dust or wildfires.

Owing to MEDC and HICs benefiting from superior healthcare infrastructure, certain diseases associated with PM pollution can be treated, resulting in reduced mortality rates compared with less developed countries. This theory is supported by Wood et al. (1999) who suggested that people from lower socioeconomic groups with less education and lower occupational status, are much more prone to mortality from treatable conditions; many of which can be linked to PM pollution. People from less developed regions suffer more from PM pollution and AAP overall due to their overall ambient mean levels being higher. Thus, their level of exposure to PM is generally considerably higher as established in this report and similar studies (Etchie et al., 2017). Furthermore, globally, people of lower socioeconomic class suffer more from effects associated with AAP and PM pollution (Adler and Newman, 2002 and Li et al., 2018). Within less developed countries, this is especially the case, where mortality rates are highest among this group (Etchie et al., 2017). This could be due to this group's inability to afford housing in more affluent, less congested neighbourhoods, instead having to live in traffic heavy, densely populated 'less desirable' neighbourhoods within areas of industry (industrial estates/corridors), or areas surrounded by waste dumpsites (Adler and Newman, 2002 and Li et al., 2018). Many of these less desirable areas, especially in India are nearby major production facilities or roads (Mahalingaiah et al., 2014). This could affect mortality greatly; a study by Mahalingaiah et al., 2014 found women living within 50 metres of a major road had an increased risk of $38 \%$ of CVD mortality compared with women living $>500 m$ away. Overall, lower income groups have a higher exposure to AAP and PM pollution, and are less likely to have access to treatment or be able to afford treatment for diseases associated with AAP/PM pollution, culminating in higher per capita mortality rates in the less developed and poorer countries. This assessment is supported by a World Bank study on air pollution (2016).

To add to this point, poorly planned rapidly urbanized areas in industrial countries, such as China and 273 India, have extremely high ambient levels in densely populated and crowded areas, further exposing 274 populations to high levels of PM (Etchie et al., 2017). The burning of solid biomass fuels in lesser 275 developed regions also contributes greatly to ambient PM levels and thus overall mortality rates 276 (Burnett et al., 2014).

\subsection{Economic losses from AAP}


Economic losses associated with AAP are substantial in each of the countries. The World Bank (2016) reports a global economic loss in excess of $\$ 5$ trillion annually due to overall air pollution. The same study reported that East Asian and Pacific countries make up the lion's share of this total, \$2.306 trillion, with LMICs as a whole accounting for 59\% of the overall global total. NICs like China and India represent the majority of this loss, with the equivalent of $9.92 \%$ (\$1.59tn) and $7.69 \%$ (\$505bn) of their GDP lost respectively annually. The two LEDCs in this study, Pakistan and Nigeria, see a loss of $5.88 \%$ (\$47bn) and 3.99\% (\$37bn) respectively. Lastly the UK, USA and Uganda, the two MEDCs and the LDC, used in this study, see some of the lowest economic losses at 3.21\% (\$76bn), 2.8\% (\$454bn) and 3.16\% (\$1.9bn) of GDP respectively annually (Figure 4). It is worth noting that these figures only include welfare losses, are from 2013 and are adjusted for PPP (purchasing power parity). Furthermore, limited data exists for Uganda potentially leading to inaccuracies in this reporting.

289

290

Figure 4 Percentage of GDP and total USD lost (in billions) annually in the observed countries in this study due to AAP. Graph constructed from data taken from the World Bank database (2016).

\subsection{Mitigation strategies}

Economic growth in MEDCs/HICs has led to a substantial rise in car ownership. An example of this is the UK; between 1950 and 2014, the number of cars in the UK grew from 4 million to over 35 million (UK Department for Transport, 2015 and Rieuwerts, 2016). Whilst advancements in technology in the automobile industry help reduce vehicular emissions, an example being Norway where $9 \%$ of all cars 
300

301

302

303

304

305

306

307

308

309

310

311

312

313

314

315

316

317

318

319

320

321

322

323

324

325

326

327

328

329

330

331

332

purchased in 2014 were 'zero emission' electric models (Norwegian Department for Transport, 2014), the vast majority of cars still contribute considerably to AAP (Rieuwerts, 2016). Furthermore, in recent times, car makers, most notably Volkswagen, have been convicted of providing false emission and pollution figures for their diesel models leading to an unanticipated, unexpected rise in the release of harmful air pollutants from these vehicles (US EPA, 2017).

Therefore, a particularly productive way of mitigating PM pollution would be to reduce emissions from road transport. Plans that have been proven to work include the Congestion Charge Scheme (CCS), the Low Emission Zone (LEZ) and the Ultra Low Emission Zone (ULEZ) in London. Furthermore, at the time of writing there are 250 LEZs operating in Europe (Transport and Environment, 2019). The CCS has been seen to reduce mean ambient $\mathrm{PM}_{10}$ significantly with a reduction of $0.8 \mu \mathrm{g} / \mathrm{m}^{3}$ around London observed the year after its introduction (2003) (Atkinson et al., 2009; Health Effects Institute, 2011). This is mainly due to the dis-incentivisation of vehicle use within this area due to the CCS resulting in a reduction of up to $30 \%$ in downtown car traffic, reducing overall PM emissions and also causing reductions in emissions from slow moving or stationary vehicles (Guttikunda et al., 2014). Furthermore, the LEZ led to a reduction of $0.75 \mu \mathrm{g} / \mathrm{m}^{3}$ in $\mathrm{PM}_{10}$ around London 2 years after its implementation in 2010 (HEI, 2011).

Another way of reducing air pollution from road transport could include introducing higher taxation for diesel and other 'very high/high energy fuels'. A study in Australia found that a tax of 53 cents (very high energy) or 38 cents (high energy) per litre on these fuels could reduce air pollutants by up to $40 \%$ (Barnett and Knibbs, 2014). It is worth noting that this study did not specifically look at effects on PM but did imply a reduction in road traffic and thus a reduction in overall resulting PM pollution.

In Tokyo, Japan, to improve air quality a 'diesel control ordinance' was established in 2003. This restricted the use of diesel cars within the city limits (Yorifugi et al., 2017). In the 10 years that followed (2003-2013), a 44\% drop in PM levels from traffic was observed. Furthermore, when mortality rates were compared with another Japanese major city, Osaka, and adjusted for population size, it was observed that cardiovascular mortality had dropped by $11 \%$ (Yorifugi et al., 2017). Osaka followed suit and introduced similar legislation prohibiting and restricting diesel cars later on in 2009, so this figure would be higher if compared with other cities without this type of restriction. The overall usage and encouragement of cleaner and more efficient vehicles and fuels has proven to be a very effective method, especially in cities, to combat air pollution. A more drastic option would be to ban all high polluting vehicles and fuels entirely (Rieuwerts, 2016; Yorifugi et al., 2017). In Norway, political parties are making clear their intentions on doing this with a possible ban on the sale of all fossil fuel powered cars potentially being introduced by 2025 (Rieuwerts, 2016). 
Speed limits are also effective tools for reducing road-based emissions with a reduction of up to $17.1 \%$ seen in $\mathrm{PM}_{10}$ emissions as a result of the introduction of a variable speed limit in Barcelona, Spain (Bel and Holst, 2018). Improving overall public transport infrastructure is found to substantially reduce air pollution in HICS/MEDCs, with a study by Lalive et al. (2017) finding up to a $10 \%$ decrease in air pollutants due to improved rail links. The study looked at Germany between 1994 and 2004 following an ambitious expansion of their rail network, increasing the overall number of operational trains from 11,512 to 17,526 . Other means of reducing PM pollution in MEDCs/HICs would be to increase the usage of clean renewable energy like solar and wind energy (Rieuwerts, 2016). Technological advancements in recent years have resulted in the costs of renewable energy being reduced drastically, and in some cases becoming cheaper to implement than non-renewable alternatives (Narayan and Doytch, 2017). However, local level pushback, especially in the UK, saw more than half of all wind farm applications rejected in 2014 in the UK (Fabian Society, 2015). A study in Portugal found a possible 3.5\% reduction in $\mathrm{PM}_{10}$ pollution as a result of using high efficiency 'de-dusters' in certain sectors like energy production or construction (Duque et al., 2016).

Any measures to restrict personal transport requires improvements in public transport which have been shown to have direct air quality benefits. A study in Beijing found a reduction of $15 \%$ in commute time in vehicles due to the expansion of the subway train system in the city between 2009-2015 (Yang et al., 2018). This resulted in decreased vehicular emissions and thus reduced PM pollution. Another study by Guttikunda et al. (2014) found increased taxation of highly polluting cars in China was also a very effective in reducing road transport. These strategies have resulted in substantial reductions in road-based PM emissions and an improvement in the cities PM levels from transport in contrast to India. A study in Mexico City looking at how the introduction of the 'Bus Rapid Transport' (BRT) network reduced pollution in the city found a reduction of up to $17.9 \%$ in $\mathrm{PM}_{2.5}$ pollution and up to $9.2 \%$ in $\mathrm{PM}_{10}$ pollution. These figures were observed following its introduction in 2005 within $2.5-10 \mathrm{~km}$ of the routes (Bel and Holst, 2018). The network saw a rise in users from 34 million in 2005 to around 260 million in 2014 (Bel and Holst, 2018), reducing journeys made by car and reducing overall traffic.

The re-suspension of dust is also a serious problem in LMICs and accounts for a large share of their PM pollution. Paving roads is the most straightforward mitigation strategy as this reduces dust resuspension substantially (Central Pollution Control Board, 2010). However, this is often a very costly

362 process; a cheaper short-term strategy could be to use light or heavy-duty vehicles to vacuum dust or 363 spray roads with a high dust content with water to reduce re-suspension (Guttikunda et al., 2014). and PM pollution. Thus, educational programs to inform about the dangers of burning fuels indoors 
alongside education on non-communicable diseases associated with air pollution and possible treatments available could prove to be very effective.

368 A study looking at replacing old conventional wood burning fireplaces with more efficient 'certified' wood burning appliances, found a possible $80 \%$ reduction in $\mathrm{PM}_{10}$ emissions from this source as a result (Duque et al., 2016). As a high number of people utilise conventional wood burning as a form of heat in LEDCs and LDCs (Ngele and Onwu, 2015), this method could prove very effective in reducing exposure and overall levels of AAP and PM pollution. A way of reducing PM pollution from the burning of coal could be to introduce flue gas desulphurization systems into existing coal fired power stations (Guttikunda et al., 2014). In India alone, this could reduce PM pollution from these power stations by up to $40 \%$ (Guttikunda et al., 2014).

Legislation and policy are arguably the most effective methods for reducing overall AAP. Examples of this can be found in the USA and the EU, with the USA Air Pollution Control Act (1955) and the EU's AAQD (2008/50/EC). The USA was one of the first countries to introduce legislation to mitigate air pollution with the Air Pollution Control Act (1955) and then the Clean Air Act (1963). These acts began the process of investigating and monitoring air pollution and eventually led to the establishment of National Ambient Air Quality Standards in a 1970 amendment (US EPA, 2018). The US EPA also set an annual mean limit of $12 \mu \mathrm{g} / \mathrm{m}^{3}$ for ambient $\mathrm{PM}_{2.5}$ (US EPA, 2018b). If the current day $\mathrm{PM}_{2.5}$ limit established in the USA were followed worldwide, it is estimated that 1.443 million deaths could be averted yearly (Etchie et al., 2017). In part thanks to targets and mitigation strategies laid out in updated versions of the US Clean Air Act (1963), PM 2.5 levels dropped by 42\% between 2000-2016 (US EPA, 2017). This has resulted in the USA meeting this target in all of its major (above $1 \mathrm{~m}$ people) cities. It also abides by the WHO AQG for $\mathrm{PM}_{10}$ in each of its major cities. It is important to note that neighbourhoods in some of these cities do reach and exceed these limits, with Chelsea in New York being an example with annual mean levels up to 22\% above the limit in 2014 (New York Health and Environment Department, 2018).

It must however be noted that the efficacy of legislation is dependent on the responsible governing body enforcing it. For example, the current administration of the USA has publicly stated its scepticism over climate change and their doubts over the validity of maintaining environmental protections. Therefore, it is doubtful that further meaningful legislation will be passed, or current legislation will be properly enforced during the current presidential term (2017-2021), potential reversing progress made thus far. Studies indicate there is a link between corruption and air pollution in many LMICs, especially LEDCs and LDCs (Candau and Dienesch, 2017). Any legislation restricting air pollution may lead to restrictions on production or increasing costs of production. Corporations whom rely heavily on cheap manufacturing facilities may look unfavourably upon this and therefore use their power to oppose and 
400

401

402

403

404

405

406

407

408

409

410

411

412

413

414

415

416

417

418

419

420

421

422

block it. Improved governance and corporate accountability within these countries as well as regulation by international bodies to reduce this corruption could eliminate this malpractice. From a purely fiscal standpoint, it is worth noting that this type of legislation is also extremely cost effective with a return on investment of $\sim 30 x(E P A, 2011)$.

Education, inequality and socioeconomic status, have been strongly linked with PM pollution exposure (Huang et al., 2017; Etchie et al., 2017). As there are higher levels of education and access to universal, often free, healthcare in MEDCs, this would naturally result in both lower rates of exposure and lower overall levels due to concern over this exposure. In a similar vein, the findings of this study could be interpreted to mirror that of the highly debated theoretical Environmental Kuznets curve, which suggests that as a countries wealth increases, whilst initially it experiences an uptick in environmental degradation, it reaches a peak when the inverse occurs (Dinda, 2004 and Aruga, 2019). However, it should be noted that this theory has come under considerable scrutiny, with some questioning its validity, especially in regard to particulate concentrations (Stern, 2004 and Stern 2015).

Finally, it should be noted that most of the examples provided above have been applied in countries that are more affluent with governments committed to improving air quality. In poorer economies without outside investment in most cases there is neither the resources, nor potentially the political will, to improve air quality, hence the observation in air borne pollutants provided in this study. Similar mitigation strategies used by HICS/MEDCs can be deployed in LMICs to combat AAP and more specifically PM pollution. However, issues related to funding, corruption and poor governance require overcoming first (Hunt, 2007, Olken and Pande 2012; Borja, 2017).

\section{Conclusions}

The data provided in this study lead to the following conclusions:

1) AAP varies based on developmental level, with substantially higher $P M_{2.5}$ and $P M_{10}$ levels being observed in Lower Middle-Income Countries (which include NICs, LEDCs and LDCs). This may be due to socio-economic factors, with a lack of desire to reduce AAP and a lack of legal standards or limits for AAP being the primary drivers. Despite long term costs of air pollution vastly outstripping the costs of mitigating air pollution (by up to 30 times), and the associated socio-economic costs being so high, many countries within the LMIC bracket do not consider AAP or PM pollution to be of paramount immediate importance.

2) It is clear countries with substantial inputs from natural sources (resuspended dust), such as Nigeria, have the worst AAP and highest PM levels in some areas. However, this being said, 
the most deaths attributable to PM and AAP overall come from heavily industrialised countries such as China and India due to their population density in heavily polluted areas.

3) PM pollution in Lower Middle-Income Countries may be attributed to factors such as poor

\section{Acknowledgements}

The authors would like to acknowledge the support of the Environmental Science team at the University of Plymouth regarding advice and access to data for this study.

\section{Conflict of interest declaration}

The authors declare that there are no conflicts of interest associated with this research or publication.

\section{References}

Adler, N.E. and Newman, K. Socioeconomic disparities in health: pathways and policies. Health Affairs, 2002, 21, pp. 60-76.

Adeniran, J., Yusuf, R. and Olajire, A. (2017). Exposure to coarse and fine particulate matter at and around major intra-urban traffic intersections of Ilorin metropolis, Nigeria. Atmospheric Environment, 166, pp. 383-392.

Apte, J. S., Marshall, J. D., Cohen, A. J. and Brauer, M. Addressing global mortality from ambient $\mathrm{PM}_{2.5}$. Environ. Sci. Technol. 2015, 49, pp. 8057-8066.

Atkinson, R., Barratt, B., Armstrong, B., Anderson, H., Beevers, S., Mudway, I., Green, D., Derwent, R., Wilkinson, $\mathrm{P}$. and Tonne, $\mathrm{C}$. The impact of the congestion charging scheme on ambient air pollution concentrations in London. Atmos. Environ., 2009, 43(34), pp. 5493-5500.

Aruga, K.,. Investigating the Energy-Environmental Kuznets Curve Hypothesis for the Asia-Pacific Region. Sustainability, 2019, 11(8), pp. 2395. 
Barmpadimos, I., Hueglin, C., Keller, J., Henne, S., and Prévôt, A.S.H. Influence of meteorology on PM 10 trends and variability in Switzerland from 1991 to 2008. Atmos. Chem. and Physics, 2011, 11, 18131835.

Barnett, A. and Knibbs, L. Higher fuel prices are associated with lower air pollution levels. Environ. Int., 2014, 66, pp. 88-91.

Bel, G. and Holst, M. Evaluation of the impact of 'Bus Rapid Transit' on air pollution in Mexico City. Transport Policy, 2018, 63, 209-220.

Bourdrel, T., Bind, M., Bejot, Y., Morel, O. and Argacha, J. Cardiovascular effects of air pollution. Arch. Cardiovascular Diseases, 2017, 1018, 1-9.

Burnett, R. T., Pope, C. A., Ezzati, M., Olives, C., Lim, S. M., Mentha, S., Shin, H. H., Singh, G., Hubbell, B., Brauer, M., Anderson, H. R., Smith, K. R., Kan, H., Laden, F., Pruss-Ustun, A., Turner, M. C., Thun, M. and Cohen, A. An integrated risk function for estimating the global burden of disease attributable to ambient fine particulate matter exposure. Environ. Health Persp., 2014, 122 (4), 397-403.

Borja, K. Corruption indicators, foreign capital, and economic growth in developing countries. J. Develop. Areas, 2017, 51(4), pp. 95-107.

Candau, F. and Dienesch, E. Pollution haven and corruption paradise. J. Environ. Econ. \& Man., 2017, 85, 171-192.

CPCB (Central Pollution Control Board) (2010). Air quality assessment, emission inventory and source apportionment study for Bangalore city. Bangalore: CPCB.

Cheng, Z., Luo, L., Wang, S., Wang, Y., Sharma, S., Shimadera, H., Wang, X., Bressi, M., de Miranda, R., Jiang, J., Zhou, W., Fajardo, O., Yan, N. and Hao, J. Status and characteristics of ambient PM 2.5 pollution in global megacities. Environ. Int., 2016, 89-90, pp.212-221.

Clean Air Act 1956. [on line], Available at: https://www.legislation.gov.uk/ukpga/Eliz2/4-5/52/enacted (Accessed 5 Nov. 2020).

Council Directive 2008/50/EC of 21 May 2008 on ambient air quality and cleaner air for Europe (2008) OJ L 152/1.

DEFRA. Air Pollution in the UK 2016. Available at: https://ukair.defra.gov.uk/assets/documents/annualreport/air_pollution_uk_2016_issue_1.pdf (Accessed 22 Feb. 2018). 2017.

Department of Health: Committee on the Medical Effects of Air Pollution. Handbook on Air Pollution and Health. London: The Stationery Office. 2017.

Department of the Environment. Expert panel on Air Quality Standards: Particles. HMSO: London. 1995.

Dinda, S. Environmental Kuznets Curve Hypothesis: A Survey. Ecological Economics, 2004, 49(4), pp. 431-455. 
Duque, L., Relvas, H., Silveira, C., Ferreira, J., Monteiro, A., Gama, C., Rafael, S., Freitas, S., Borrego, C. and Miranda, A. Evaluating strategies to reduce urban air pollution. Atmos. Environ., 2016, 127, 196204.

Etchie, T., Sivanesan, S., Adewuyi, G., Krishnamurthi, K., Rao, P., Etchie, A., Pillarisetti, A., Arora, N. and Smith, K. The health burden and economic costs averted by ambient $\mathrm{PM}_{2.5}$ pollution reductions in Nagpur, India. Environ. Int., 2017, 102, 145-156.

EU (2010) European Union Industrial Emissions Directive 2010/75/EU of the European Parliament and the Council on Industrial Emissions.

EU (2018) European Union Regulation (EU) 2018/858 of 30 May 2018 on the approval and market surveillance of motor vehicles and their trailers, and of systems, components and separate technical units intended for such vehicles, amending Regulations (EC) No 715/2007 and (EC) No 595/2009 and repealing Directive 2007/46/EC.

Fabian Society, 2015. Transition By Consent. [online] London: Fabian Society, 1-6. Available at: (https://www.fabians.org.uk/wp-content/uploads/2015/01/TransitionByConsent final.pdf) [Accessed 18 February 2018].

Fang, D., Wang, Q., Li, H., Yu, Y., Lu, Y. and Qian, X. Mortality effects assessment of ambient $\mathrm{PM}_{2.5}$ pollution in 74 leading cities in China. Sci. Tot. Environ., 2016, 569-570, 1545-1552.

Giannadaki, D., Lelieveld, J. and Pozzer, A. Implementing the US air quality standard for $\mathrm{PM}_{2.5}$ worldwide can prevent millions of premature deaths per year. Environ. Health, 2016, 15(1), 2-11.

Guttikunda, S., Goel, R. and Pant, P. Nature of air pollution, emission sources, and management in the Indian cities. Atmos. Environ., 2014, 95, 501-510.

Harrison, R., Giorio, C., Beddows, D. and Dall'Osto, M. Size distribution of airborne particles controls outcome of epidemiological studies. Sci. Tot. Environ. 2010, 409(2), 289-293.

Health Effects Institute. The impact of the congestion charging scheme on air quality in London. Part 1. Emissions modelling and analysis of air pollution measurements. Boston: Health Effects Institute, 2011, 5-88.

Huang, L., Rao, C., van der Kuijp, T. J, Bi, J. and Liu, Y. (2017). A comparison of individual exposure, perception, and acceptable levels of $\mathrm{PM}_{2.5}$ with air pollution policy objectives in China. Environ. Res., $2017,157,78-86$.

Hunt, J. How corruption hits people when they are down. J. Dev. Econ. 2007, 84(2), 574-589.

Kirenga, B., Meng, Q., van Gemert, F., Aanyu-Tukamuhebwa, H., Chavannes, N., Katamba, A., Obai, G., Molen, T., Schwander, S. and Mohsenin, V. The State of Ambient Air Quality in Two Ugandan Cities: A Pilot Cross-Sectional Spatial Assessment. Int. J. Environ. Res. and Pub. Health, 2015, 12(7), 8075-8091.

Lalive, R., Luechinger, S. and Schmutzler, A. Does expanding regional train service reduce air pollution?. J. of Environ. Econ. and Man. 2017, 50, pp. 2-10.

Li, V., Han, Y., Lam, J., Zhu, Y. and Bacon-Shone, J. Air pollution and environmental injustice: Are the socially deprived exposed to more PM 2.5 pollution in Hong Kong? Environ. Sci. \& Policy, 2018, 80, 5361. 
Macedo, J. Planning a Sustainable City. J. Planning History, 2013, 12(4), 334-353.

Mahalingaiah, S., Hart, J., Laden, F., Terry, K., Boynton-Jarrett, R., Aschengrau, A. and Missmer, S. Air Pollution and Risk of Uterine Leiomyomata. Epidemiology, 2014, 25(5), 682-688.

Narayan, S. and Doytch, N. An investigation of renewable and non-renewable energy consumption and economic growth nexus using industrial and residential energy consumption. Energy Economics, 2017, $68,160-176$.

Ngele, S. and Onwu, F. Comparison of particulate matter levels in major urban centres in Eastern Nigeria. Int. J. of Environ. Sci. 2015, 5(4), 765-773.

Norwegian Department of Petroleum and Energy (2012). National Renewable Energy Action Plan under Directive 2009/28/EC. Oslo: Ministry of Energy and Petroleum.

Olken, B. and Pande, R. Corruption in Developing Countries. Boston: MIT. 2012.

Rieuwerts, J. An air that kills: Our invisible air pollution crisis. $1^{\text {st }}$ ed. UK: self-published. 2016

Roux, J., Bard, D., Le Pabic, E., Segala, C., Reis, J., Ongagna, J., de Sèze, J. and Leray, E. Air pollution by particulate matter PM 10 may trigger multiple sclerosis relapses. Environ. Res. 2017, 156, 404-410.

RCP (Royal College of Physicians) Every breath we take: the lifelong impact of air pollution. London: RCP. 2016

Soltani, A. and Sharifi, E. A case study of sustainable urban planning principles in Curitiba (Brazil) and their applicability in Shiraz (Iran). Int. J. Dev. and Sustain. 2018, 1(2), 2-13.

Stern, D. The Environmental Kuznets Curve after 25 Years. Journal of Bio-economics, 2017, 19, pp. 728.

Stern, D. The Rise and Fall of the Environmental Kuznets Curve. World Development, 2004, 32(8), pp. 1419-1439.

Transport and Environment. Low-Emission Zones are a success - but they must now move to zeroemission mobility. [online] Available at: https://www.transportenvironment.org/sites/te/files/publications/201909 Briefing LEZZEZ final.pdf (Accessed 28 Jan 2020). 2019.

United Kingdom Department for Transport. Vehicle Licensing Statistics 2016. London: UK DfT. 2016

United Nations. Country classification; Data sources, country classifications and aggregation methodology. United Nations: Geneva. 2014.

United Nations (2019) Health as a political driver for increased ambition on climate change, in the UN Secretary-General's 2019 Climate Summit. [online] Available at: https://www.who.int/globalchange/commit/Proposed-Commitments-SPD-Coalition.pdf?ua=1\&ua=1 (accessed 5 Nov., 2020).

US EPA. The benefits and Costs of the Clean Air Act from 1990 to 2020. US EPA: Washington DC. 2011. 
625 US EPA. Volkswagen Clean Air Act Civil Settlement. [online] Available at: 626 https://www.epa.gov/enforcement/volkswagen-clean-air-act-civil-settlement. 2017 (Accessed 26 Sep. 2017).

US EPA The Clean Air Act. [online] Available at: https://www.epa.gov/clean-air-act-overview/clean-airact-text 2018. (Accessed 17 Jan. 2018).

US EPA (2018b). Particulate Matter Pollution. [online] Available at: https://www.epa.gov/pmpollution/particulate-matter-pm-basics, 2017b, Accessed 17 Jan. 2018).

World Bank. The Cost of Air Pollution: Strengthening the Economic Case for Action. [online] Seattle: The World Bank, pp.1-122. Available at: https://openknowledge.worldbank.org/bitstream/handle/10986/25013/108141.pdf?sequence=4\&is Allowed=y, 2016, (Accessed 26 Feb. 2018).

World Bank. DataBank / The World Bank. [online] Available at: http://databank.worldbank.org/data/home.aspx. 2016b (Accessed 28 Feb. 2018).

WHO (World Health Organisation). Review of Evidence on Health Aspects of Air Pollution - REVIHAAP Project. Available at: http://www.euro.who.int/data/assets/pdf file/0004/193108/REVIHAAP-Finaltechnical-report-final-version.pdf. 2013, (Accessed on 31 Sep. 2017).

World Health Organization Office for Europe. Ambient air pollution: A global assessment of exposure and burden of disease. Bonn: World Health Organization. 2016

WHO (World Health Organization). WHO Global Urban Ambient Air Pollution Database (update 2016). [online] Available at: http://www.who.int/phe/health topics/outdoorair/databases/cities/en/, 2017, (Accessed 1 Jul. 2017).

Yang, J., Chen, S., Qin, P., Lu, F. and Liu, A. The effect of subway expansions on vehicle congestion: Evidence from Beijing. J. Environ. Econ. Man. 2018, 88, 114-133.

Yin, P., He, G., Fan, M. and Chu, K. Particulate air pollution and mortality in 38 of China's largest cities: time series analysis. British Med. J., 2017, 1, 1379.

Yorifuji, T., Kashima, S., Diez, M., Kado, Y., Sanada, S. and Doi, H. Prenatal exposure to outdoor air pollution and child behavioural problems at school age in Japan. Environ. Int. 2017, 99, 192-198. 